\title{
PONTO DE COLHEITA E PERÍODO DE ARMAZENAMENTO REFRIGERADO NA QUALIDADE DE PÊSSEGOS (Prunus persica, L.) DE MESA, CV. CHIRIPÁ
}

\author{
HARVESTING STAGE AND COLD STORAGE INFLUENCES ON THE QUALITY OF \\ CHIRIPÁ PEACHES (Prunus persica, L.)
}

\section{Cesar Valmor Rombaldi ${ }^{1}$ Jorge Adolfo Silva ${ }^{2}$ Lilia Bender Machado $^{3}$ Aguinaldo Parussolo $^{4}$ Luiz Carlos Kaster ${ }^{5}$ César Luís Girardi ${ }^{6}$ Roque Danieli $^{7}$}

\section{RESUMO}

Estudou-se o efeito do ponto de colheita de pêssegos da cultivar Chiripá no potencial de armazenamento e na qualidade sensorial das frutas. Os pêssegos foram colhidos em quatro estádios de maturação $e$ armazenados sob refrigeração a $O^{\circ} \mathrm{C} \pm 0,5^{\circ} \mathrm{C}$, por 42 dias. A cada sete dias, realizaram-se avaliações de firmeza de polpa, acidez total titulável, ocorrência de distúrbios fisiológicos (lanosidade e escurecimento da polpa) $e$ análise sensorial. Essas análises foram realizadas 24 e 72 horas após a retirada das frutas da câmara frigorífica. Os pêssegos colhidos em estádios menos avançados de maturação apresentaram maiores valores de firmeza de polpa durante o armazenamento, mas apresentaram maiores índices de lanosidade. Já os pêssegos colhidos mais maduros tiveram maiores perdas de firmeza de polpa, porém obtiveram melhores notas na avaliação sensorial.

Palavras-chave: maturação, distúrbios fisiológicos, colheita.

\section{SUMMARY}

The purpose of this experiment was to evaluate the effect of the harvest point of Chiripa peach on the storage potential and sensory quality. Fruits were harvested in four ripening stages and stored at $0^{\circ} \mathrm{C} \pm 0,5^{\circ} \mathrm{C}$ during 42 days. The evaluated characteristics (each 7 days) were: fruit firmness, titratable acidity, physiological disorders (internal browing and woolly breakdown) and sensory analysis. These analyses were done after 24 and 72 hours shelf life. Peaches harvested in less mature ripening stages showed higher fruit firmness and higher incidence of woolly breakdown than fruit harvested in more mature stages, but these fruits showed the best sensory quality.

Key words: ripening, physiological disorders, harvest.

\section{INTRODUÇÃO}

A cultivar de pêssego "tipo mesa" Chiripá, criada pela UEPAE de Cascata (MEDEIROS \& RASEIRA, 1998), é a mais plantada no Sul do Brasil. Ela produz frutas médio-grandes, redondoovaladas, com peso variando de $100 \mathrm{~g}$ a $190 \mathrm{~g}$ e com alto acúmulo de sólidos solúveis, em torno de $15^{\circ}$ Brix. A polpa dessas frutas é firme, branca, com região avermelhada junto ao caroço. A epiderme tem coloração de fundo creme-esverdeada e avermelhada na superfície, atingindo até $30 \%$ da fruta. Na maioria das regiões, a colheita é realizada entre 15 de dezembro e 15 de janeiro, período em que se registra o maior volume de oferta de pêssegos, de ameixas e de nectarinas, diminuindo o preço de comercialização.

Por tratar-se de uma fruta climatérica, de metabolismo acelerado e suscetível a danos mecâni-

\footnotetext{
${ }^{1}$ Engenheiro Agrônomo, PhD., Professor Adjunto do Departamento de Ciência e Tecnologia Agroindustrial (DCTA), Universidade Federal de Pelotas (UFPEL), CP 354, 96010-900, Pelotas, RS. E-mail: cesarvr@ufpel.tche.br. Autor para correspondência.

${ }^{2}$ Engenherio Agrônomo, MSc., DCTA-UFPEL.

${ }^{3}$ Engenheiro Agrônomo, aluno do Programa de Pós-graduação em Agronomia, DFT-UFPEL.

${ }^{4}$ Químico Industrial de Alimentos, aluno do Programa de Mestrado em Ciência e Tecnologia Agroindustrial (PMCTA), DCTA-UFPEL.

${ }^{5}$ Engenheiro Agrônomo, MSc., EMATER, Farroupilha - RS.

${ }^{6}$ Engenheiro Agrônomo, MSc., Pesquisador da EMBRAPA-CNPUV.

${ }^{7}$ Engenheiro Agrônomo, MSc., Escola Agrotécnica Federal Presidente Juscelino Kubitschek, Bento Gonçalves - RS.
} 
cos, há necessidade da adoção de práticas de manejo na colheita e pós-colheita para prolongar o período de oferta, visando ao abastecimento dos mercados local e nacional.

$\mathrm{O}$ armazenamento refrigerado tem sido o método mais utilizado para reduzir as perdas póscolheita. Entretanto, três problemas principais têm sido relatados: 1) perda de firmeza da polpa (BENARIE \& SONEGO, 1980; MEREDITH et al., 1989; MANESS et al., 1993; SONEGO et al., 1994; TAYLOR et al., 1994); 2) ocorrência de distúrbios fisiológicos, especialmente lanosidade e escurecimento interno (ROBERTSON et al., 1992; LURIE, 1993; LUCHSINGER et al., 1996); e, 3) podridões (GOTTINARI et al., 1998). Várias alternativas, como o emprego de atmosferas modificada (LURIE, 1993) e controlada (LURIE, 1992), aquecimentos intermitentes e choques de $\mathrm{CO}_{2}$ (TONUTTI $\boldsymbol{e}$ t al., 1998) têm sido testadas para reduzir esses problemas. Os resultados são variados, indicando, em alguns casos, limitações econômicas, diminuição da cadência operacional, baixa operacionalidade e falta de reprodutibilidade (MITCHELL \& CRISOTO, 1995).

A colheita de pêssegos em estádios menos avançados de maturação permite manter a firmeza de polpa, mas, dependendo da cultivar, das condições edafoclimáticas, das condições e do período de estocagem, pode induzir a ocorrência de elevados percentuais de frutas com distúrbios fisiológicos (PRATELLA et al., 1988; SOUTY et al., 1990; MURRAY \& VALENTINI, 1998). Também, de maneira geral, há uma elevada correlação inversa entre antecipação da colheita e a qualidade sensorial das frutas (PRATELLA et al., 1988; SOUTY et al., 1990).

A colheita tardia permite a obtenção de frutas com qualidade sensorial superior, mas reduz a conservabilidade (PRATELLA et al., 1988). Por isso, há necessidade, para cada cultivar e em cada região de produção, de determinar as características das frutas no momento da colheita, também denominado de ponto de colheita, visando ao armazenamento a curto, médio e longo prazo (SALVADOR $\boldsymbol{e} t$ al., 1998).

A estrutura da cadeia de produção de pêssegos de mesa no RS é caracterizada por pequenomédias propriedades, com sistema diversificado de produção, câmaras frigoríficas de atmosfera convencional e mercado consumidor nacional localizado, geralmente, há mais de $500 \mathrm{~km}$ das unidades de pro- dução. Surge, então, a necessidade de geração e calibração de condições para a conservação dessa fruta sob refrigeração.

Dentro desse contexto, buscou-se estudar o influência do ponto de colheita, ou estádio de maturação dos pêssegos da cultivar Chiripá, no período de armazenamento refrigerado e na qualidade das frutas.

\section{MATERIAL E MÉTODOS}

O experimento foi conduzido no Departamento de Ciência e Tecnologia Agroindustrial da Universidade Federal de Pelotas, em colaboração com a EMBRAPA - Uva e Vinho de Bento Gonçalves.

Foram utilizados pêssegos da cultivar Chiripá provenientes de pomares comerciais da Região Nordeste do RS. Como havia baixa uniformidade de maturação das frutas, procederam-se duas colheitas: a primeira em 17/12, e a segunda em 24/12. Em cada uma delas, as frutas foram selecionadas em dois estádios de maturação. Dessa operação, resultaram quatro estádios de maturação (I, II, III e IV), caracterizados pela coloração de fundo, firmeza de polpa (FP), sólidos solúveis totais (SST) e acidez total titulável (ATT): estádio I - frutas com coloração de fundo verde-opaca, FP entre 70 e $80 \mathrm{~N}$, SST entre 12 e $12,5^{\circ}$ Brix e ATT de 10 a $12 \mathrm{cmol} . \ell^{-1}$; estádio II - frutas com coloração de fundo verdeesbranquiçada, 60 a $70 \mathrm{~N}, 12,5$ a $13,5^{\circ}$ Brix e 8 a $10 \mathrm{cmol} . \ell^{-1}$; estádio III - frutas com coloração de fundo verde-esbranquiçada transparente, 45 a $60 \mathrm{~N}$, 13,5 a $14,0^{\circ}$ Brix e 6 a $8 \mathrm{cmol} . \ell^{-1}$; e estádio IV - frutas com coloração de fundo creme, 25 a $30 \mathrm{~N}, 14,0$ a $15,5^{\circ}$ Brix e 4 a $6 \mathrm{cmol} . \ell^{-1}$.

As frutas foram armazenadas em câmaras frigoríficas a $0,0^{\circ} \mathrm{C} \pm 0,5^{\circ} \mathrm{C}$ e $85-92 \%$ de umidade relativa durante 42 dias. A cada sete dias, a partir da instalação do experimento, foram coletadas, de cada estádio de maturação, amostras de 20 pêssegos com seis repetições. Avaliaram-se a firmeza de polpa (FP), acidez total titulável (ATT), sólidos solúveis totais (SST), ocorrência de lanosidade, escurecimento interno, e avaliação sensorial de acordo com a metodologia descrita por GOTTINARI et al. (1998). Essas avaliações foram realizadas 24 horas e 72 horas após a retirada das frutas da câmara e mantidas a $20^{\circ} \mathrm{C} \pm 0,5^{\circ} \mathrm{C}$. Foram consideradas frutas aptas para a comercialização, aquelas que atendiam, no conjunto, os seguintes critérios: firmeza de polpa 
superior a $20 \mathrm{~N}$, ocorrência de lanosidade e de escurecimento interno, cada um inferior a $10 \%$.

$\mathrm{O}$ experimento seguiu um delineamento inteiramente casualizado, em esquema fatorial $4 \times 7$ (estádios de maturação x períodos de armazenamento refrigerado). Para as variáveis escurecimento e lanosidade, as quais são medidas em percentual, os dados foram transformados segundo arco seno da raiz de $\mathrm{x} / 100$.

Os dados obtidos foram submetidos à análise de variância e interações. Utilizou-se o teste de Duncan, em nível de 5\% de probabilidade, para a comparação múltipla das médias.

\section{RESULTADOS E DISCUSSÃO}

Para as cinco variáveis analisadas, a interação entre os quatro estádios e os sete períodos de armazenamento refrigerado apresentou-se significativa.

Os pêssegos colhidos no estádio I mantiveram a firmeza de polpa acima de $20 \mathrm{~N}$ durante os 42 dias de armazenamento refrigerado (Tabela 1A) e após 72 horas de retirada da câmara (Tabela 1B). As frutas colhidas no estádio II, também, mantiveram elevados valores de firmeza de polpa, sempre acima de $20 \mathrm{~N}$, durante o armazenamento refrigerado (Tabela 1A). Entretanto, quando essas frutas foram retiradas da câmara frigorífica houve significativa redução da firmeza de polpa, atingindo $14,40 \mathrm{~N}$ após 28 dias de armazenamento refrigerado, mais 4 dias a $20 \pm 0,5^{\circ} \mathrm{C}$ (Tabela 1B).
As maiores reduções na firmeza da polpa ocorreram nas frutas colhidas nos estádios III e IV. Durante o armazenamento refrigerado, os pêssegos colhidos no estádio III mantiveram a firmeza de polpa acima de $20 \mathrm{~N}$ até o $21^{\circ}$ dia de armazenamento refrigerado (Tabela 1A). A retirada das frutas da câmara frigorífica resultou numa significativa redução da firmeza de polpa, atingindo 18,43N após 14 dias de armazenamento refrigerado, mais 72 horas a $20 \pm 0,5^{\circ} \mathrm{C}$. Para frutas colhidas no estádio IV, esses decréscimos foram mais acentuados e rápidos, sendo que com 7 dias de armazenamento refrigerado, mais 72 horas a $20 \pm 0,5^{\circ} \mathrm{C}$ atingiram valores abaixo de $10 \mathrm{~N}$ (Tabela 1B). Para essas frutas, recomendam-se a colheita e comercialização/consumo imediato.

Esse comportamento é normal, já que há uma relação direta entre a evolução da maturação, a perecibilidade e a perda de firmeza da polpa (PRATELLA et al., 1988; MEREDITH et al., 1989; SOUTY et al., 1990). Entretanto, PRESSEY \& AVANTS (1978) citam que se deve associar à avaliação da firmeza de polpa outros parâmetros de qualidade, já que a maioria dos métodos destrutivos utilizados para essa determinação são influenciados pela ocorrência de lanosidade e/ou perda d'água periférica. Por essas razões, determinaram-se a acidez total titulável, o teor de sólidos solúveis totais, a ocorrência de distúrbios fisiológicos e realizou-se análise sensorial.

A acidez total titulável reduziu significativamente com a evolução da maturação, passando

Tabela 1 - Firmeza de polpa (Newtons) de pêssegos da cultivar Chiripá, armazenados sob refrigeração durante 42 dias. As avaliações foram realizadas 24 horas (A) e 72 horas (B) após a retirada dos frutos da câmara fria. Pelotas-RS. 1999.

\begin{tabular}{cccccc}
\hline \multirow{5}{*}{$\begin{array}{c}\text { Período } \\
\text { (dias) }\end{array}$} & E I & E II & E III & E IV & Média \\
\cline { 2 - 6 } & & & & & \\
\hline & & & & \\
0 & $74,00^{\mathrm{Aa} *}$ & $59,60^{\mathrm{Ab}}$ & $37,10^{\mathrm{Ab}}$ & $22,50^{\mathrm{Ad}}$ & 48,30 \\
7 & $72,00^{\mathrm{Ba}}$ & $47,43^{\mathrm{Bb}}$ & $28,69^{\mathrm{Bb}}$ & $22,50^{\mathrm{Ad}}$ & 42,65 \\
14 & $62,50^{\mathrm{Ca}}$ & $45,00^{\mathrm{Cb}}$ & $27,00^{\mathrm{Cb}}$ & $12,50^{\mathrm{Bd}}$ & 36,75 \\
21 & $61,60^{\mathrm{Ca}}$ & $41,10^{\mathrm{Db}}$ & $22,50^{\mathrm{Db}}$ & $6,20^{\mathrm{Cd}}$ & 32,85 \\
28 & $62,00^{\mathrm{Ca}}$ & $37,06^{\mathrm{Eb}}$ & $14,40^{\mathrm{Eb}}$ & & 37,82 \\
35 & $55,00^{\mathrm{Ea}}$ & $41,03^{\mathrm{Db}}$ & $12,33^{\mathrm{Fb}}$ & & 36,12 \\
42 & $57,50^{\mathrm{Da}}$ & $41,00^{\mathrm{Db}}$ & $12,33^{\mathrm{Fb}}$ & & 36,94 \\
& & & & & \\
Média & 63,51 & 44,60 & 22,05 & 15,92 & \\
CV (\%) & & 5 & 2,157 & &
\end{tabular}

B

\begin{tabular}{cccccc}
\hline \multirow{2}{*}{$\begin{array}{c}\text { Período } \\
\text { (dias) }\end{array}$} & \multicolumn{5}{c}{ Estádios (72 horas) } \\
\cline { 2 - 6 } & E I & E II & E III & E IV & Média \\
\hline & & & & & \\
0 & $67,76^{\mathrm{Aa}}$ & $41,00^{\mathrm{Ab}}$ & $22,50^{\mathrm{Ac}}$ & $14,40^{\mathrm{Ad}}$ & 36,41 \\
7 & $61,53^{\mathrm{Ca}}$ & $39,00^{\mathrm{Bb}}$ & $22,50^{\mathrm{Ac}}$ & $8,20^{\mathrm{Bd}}$ & 32,81 \\
14 & $53,46^{\mathrm{Fa}}$ & $22,60^{\mathrm{Cb}}$ & $18,43^{\mathrm{Bc}}$ & $8,10^{\mathrm{Bd}}$ & 25,65 \\
21 & $55,53^{\mathrm{Ea}}$ & $22,46^{\mathrm{Cb}}$ & $14,46^{\mathrm{Cc}}$ & $4,13^{\mathrm{Cd}}$ & 24,14 \\
28 & $57,50^{\mathrm{Da}}$ & $14,40^{\mathrm{Eb}}$ & $14,40^{\mathrm{Cb}}$ & & 28,77 \\
35 & $65,79^{\mathrm{Ba}}$ & $14,40^{\mathrm{Eb}}$ & $12,40^{\mathrm{Db}}$ & & 30,86 \\
42 & $67,79^{\mathrm{Aa}}$ & $18,50^{\mathrm{Db}}$ & $12,36^{\mathrm{Dc}}$ & & 32,88 \\
& & & & & \\
Média & 61,34 & 24,62 & 16,72 & 8,71 & \\
CV (\%) & \multicolumn{5}{c}{2,924} \\
\hline
\end{tabular}

* Médias não seguidas por mesma letra, maiúscula na coluna e minúscula na linha, dentro de cada avaliação diferem entre si pelo teste de Duncan, em nível de $5 \%$ de probabilidade de erro. 
Tabela 2 - Acidez total titulável (cmol. $\left.\ell^{-1}\right)$ de pêssegos da cultivar Chiripá, armazenados sob refrigeração durante 42 dias. As avaliações foram realizadas 24 horas (A) e 72 horas (B) após a retirada dos frutos da câmara fria. Pelotas-RS. 1999.

A

\begin{tabular}{cccccc}
\hline \multirow{5}{*}{$\begin{array}{c}\text { Período } \\
\text { (dias) }\end{array}$} & E I & E II & E III & E IV & Média \\
\cline { 2 - 6 } & & & & & \\
\hline & & & & \\
0 & $12,00^{\mathrm{Aa} *}$ & $9,00^{\mathrm{Ab}}$ & $6,00^{\mathrm{Cc}}$ & $4,00^{\mathrm{Cd}}$ & 7,75 \\
7 & $10,00^{\mathrm{Ca}}$ & $7,00^{\mathrm{Cb}}$ & $5,00^{\mathrm{Dc}}$ & $5,00^{\mathrm{Bc}}$ & 6,75 \\
14 & $10,00^{\mathrm{Ca}}$ & $7,00^{\mathrm{Cb}}$ & $4,00^{\mathrm{Ed}}$ & $5,00^{\mathrm{Bc}}$ & 6,50 \\
21 & $10,00^{\mathrm{Ca}}$ & $6,00^{\mathrm{Db}}$ & $6,00^{\mathrm{Cb}}$ & $6,00^{\mathrm{Ab}}$ & 7,00 \\
28 & $9,00^{\mathrm{Da}}$ & $6,00^{\mathrm{Dc}}$ & $7,00^{\mathrm{Bb}}$ & & 7,33 \\
35 & $9,00^{\mathrm{Da}}$ & $8,00^{\mathrm{Bb}}$ & $8,00^{\mathrm{Ab}}$ & & 8,33 \\
42 & $11,00^{\mathrm{Ba}}$ & $9,00^{\mathrm{Ab}}$ & $7,00^{\mathrm{Bc}}$ & & 9,00 \\
& & & & & \\
Média & 10,14 & 7,43 & 6,14 & 5,00 & \\
CV (\%) & & \multicolumn{5}{c}{6,26} & & \\
& & & & & \\
\end{tabular}

B

\begin{tabular}{|c|c|c|c|c|c|}
\hline \multirow{2}{*}{$\begin{array}{l}\text { Período } \\
\text { (dias) }\end{array}$} & \multicolumn{5}{|c|}{ Estádios (72 horas) } \\
\hline & E I & E II & E III & E IV & Média \\
\hline 0 & $9,00^{\mathrm{Ca}}$ & $7,00^{\mathrm{Db}}$ & $4,00^{\mathrm{Ed}}$ & $5,00^{\mathrm{Bc}}$ & 6,25 \\
\hline 7 & $9,00^{\mathrm{Ca}}$ & $7,00^{\mathrm{Db}}$ & $4,00^{\mathrm{Ed}}$ & $6,00^{\mathrm{Ac}}$ & 6,50 \\
\hline 14 & $9,00^{\mathrm{Ca}}$ & $6,00^{\mathrm{Eb}}$ & $6,00^{\mathrm{Cb}}$ & $4,00^{\mathrm{Cc}}$ & 6,25 \\
\hline 21 & $9,00^{\mathrm{Ca}}$ & $8,00^{\mathrm{Cb}}$ & $7,00^{\mathrm{Bc}}$ & $4,00^{\mathrm{Cd}}$ & 7,00 \\
\hline 28 & $9,00^{\mathrm{Cb}}$ & $10,00^{\mathrm{Ba}}$ & $8,00^{\mathrm{Ac}}$ & & 9,00 \\
\hline 35 & $12,00^{\mathrm{Ba}}$ & $11,00^{\mathrm{Ab}}$ & $5,00^{\mathrm{Dc}}$ & & 9,33 \\
\hline 42 & $14,00^{\mathrm{Aa}}$ & $7,00^{\mathrm{Db}}$ & $4,00^{\mathrm{Ed}}$ & & 8,33 \\
\hline Média & 10,14 & 8,00 & 5,43 & 4,75 & \\
\hline $\mathrm{CV}(\%)$ & & & 5,12 & & \\
\hline
\end{tabular}

* Médias não seguidas por mesma letra, maiúscula na coluna e minúscula na linha, dentro de cada avaliação diferem entre si pelo teste de Duncan, em nível de $5 \%$ de probabilidade de erro.

de $12 \mathrm{cmol} . \ell^{-1}$ (estádio I) para $9 \mathrm{cmol} . \ell^{-1}$ (estádio II), $6 \mathrm{cmol} . \ell^{-1}$ (estádio III) e $4 \mathrm{cmol} . \ell^{-1}$ (estádio IV) (Tabela 2A). De maneira geral, durante o armazenamento refrigerado houve, inicialmente, diminuição da acidez total titulável, seguida de incremento. Segundo MITCHELL \& CRISOSTO (1995), durante o amadurecimento de pêssegos, a acidez segue um comportamento quadrático em que, numa primeira fase, há redução significativa da acidez, seguida de incremento, como conseqüência do aumento da atividade respiratória, seguida do acúmulo de ácidos resultantes da hidrólise da parede celular.
Excetuaram-se desse comportamento as frutas colhidas no estádio IV onde se observou um aumento da acidez total titulável durante todo o período de armazenamento refrigerado.

A ocorrência de lanosidade aumentou com o prolongamento do período de armazenamento (Tabela 3A) e atingiu a totalidade das frutas colhidas no estádio I, após 42 dias de estocagem refrigerada e 72 horas a $20 \pm 0,5^{\circ} \mathrm{C}$ (Tabela 3B). Segundo MITCHELL \& CRISOSTO (1995), esse distúrbio fisiológico é dependente da regulação da atividade de enzimas envolvidas no metabolismo da parede

Tabela 3 - Ocorrência de lanosidade (em percentual de frutas) em pêssegos da cultivar Chiripá, armazenados sob refrigeração durante 42 dias. As avaliações foram realizadas 24 horas (A) e 72 horas (B) após a retirada dos frutos da câmara fria. Pelotas-RS. 1999.

\begin{tabular}{|c|c|c|c|c|c|}
\hline \multirow{2}{*}{$\begin{array}{c}\text { Período } \\
\text { (dias) }\end{array}$} & \multicolumn{5}{|c|}{ Estádios (24 horas) } \\
\hline & E I & E II & E III & E IV & Média \\
\hline 0 & $0,00^{\mathrm{Da} *}$ & $0,00^{\mathrm{Ea}}$ & $0,00^{\text {Aa }}$ & $0,00^{\mathrm{Aa}}$ & 0,00 \\
\hline 7 & $0,00^{\mathrm{Da}}$ & $0,00^{\mathrm{Ea}}$ & $0,00^{\mathrm{Aa}}$ & $0,00^{\mathrm{Aa}}$ & 0,00 \\
\hline 14 & $0,00^{\mathrm{Da}}$ & $0,00^{\mathrm{Ea}}$ & $0,00^{\mathrm{Aa}}$ & $0,00^{\mathrm{Aa}}$ & 0,00 \\
\hline 21 & $0,00^{\mathrm{Db}}$ & $5,00^{\mathrm{Da}}$ & $0,00^{\mathrm{Ab}}$ & $0,00^{\mathrm{Ab}}$ & 1,25 \\
\hline 28 & $14,99^{\mathrm{Ca}}$ & $6,97^{\mathrm{Cb}}$ & $0,00^{\mathrm{Ac}}$ & & 7,32 \\
\hline 35 & $45,33^{\mathrm{Ba}}$ & $19,94^{\mathrm{Bb}}$ & $0,00^{\mathrm{Ac}}$ & & 21,75 \\
\hline 42 & $65,00^{\mathrm{Aa}}$ & $49,66^{\mathrm{Ab}}$ & $0,00^{\mathrm{Ac}}$ & & 38,22 \\
\hline $\begin{array}{c}\text { Média } \\
\text { CV (\%) }\end{array}$ & 17,90 & 11,65 & $\begin{array}{r}0,00 \\
15,01\end{array}$ & 0,00 & \\
\hline
\end{tabular}

B

\begin{tabular}{cccccc}
\hline \multirow{2}{*}{$\begin{array}{c}\text { Período } \\
\text { (dias) }\end{array}$} & \multicolumn{5}{c}{ Estádios (72 horas) } \\
\cline { 2 - 6 } & & E II & E III & E IV & Média \\
\hline & & & & \\
0 & $0,00^{\mathrm{Aa}}$ & $0,00^{\mathrm{Fa}}$ & $0,00^{\mathrm{Ba}}$ & $0,00^{\mathrm{Aa}}$ & 0,00 \\
7 & $0,00^{\mathrm{Ea}}$ & $0,00^{\mathrm{Fa}}$ & $0,00^{\mathrm{Ba}}$ & $0,00^{\mathrm{Aa}}$ & 0,00 \\
14 & $0,00^{\mathrm{Eb}}$ & $4,97^{\mathrm{Ea}}$ & $4,97^{\mathrm{Aa}}$ & $0,00^{\mathrm{Ab}}$ & 2,48 \\
21 & $5,00^{\mathrm{Db}}$ & $17,29^{\mathrm{Da}}$ & $5,00^{\mathrm{Ab}}$ & $0,00^{\mathrm{Ac}}$ & 6,82 \\
28 & $5,66^{\mathrm{Ca}}$ & $36,33^{\mathrm{Ca}}$ & $5,32^{\mathrm{Ab}}$ & & 15,77 \\
35 & $70,01^{\mathrm{Ba}}$ & $58,00^{\mathrm{Bb}}$ & $4,65^{\mathrm{Ac}}$ & & 44,22 \\
42 & $100,0^{\mathrm{Aa}}$ & $74,01^{\mathrm{Ab}}$ & $5,00^{\mathrm{Ac}}$ & & 59,67 \\
& & & & & \\
Média & 25,71 & 27,23 & 3,56 & 0,00 & \\
CV $(\%)$ & & & 18,44 & &
\end{tabular}

* Médias não seguidas por mesma letra, maiúscula na coluna e minúscula na linha, dentro de cada avaliação diferem entre si pelo teste de Duncan, em nível de $5 \%$ de probabilidade de erro.

Ciência Rural, v. 31, n. 1, 2001. 
celular. Quando as condições de colheita e de armazenamento favorecem a atividade de pectil-metilesterases e exopoligalacturonases em detrimento às endopoligalacturonases, aumenta a incidência de lanosidade. PRESSEY \& AVANTS (1978) verificaram que isso ocorre com maior freqüência em cultivares de pêssego de polpa branca, caroço molar, colhidos precocemente e armazenados sob refrigeração. Quando se retarda a colheita, diminui-se a incidência de lanosidade.

Baseando-se no limite máximo de $10 \%$ de frutas com lanosidade, preconizado como aceitável para a comercialização de pêssegos de mesa (SONEGO et al, 1994), as frutas colhidas no estádio I podem ser armazenadas sob refrigeração por um período de até 28 dias. Entretanto, se elas forem comercializadas em condições ambientais não controladas, normalmente com temperaturas em torno de $20^{\circ} \mathrm{C}$, esse período é reduzido a 21 dias. Para as frutas colhidas no estádio II, esses períodos são reduzidos a 21 e 14 dias, para 24 e 72 horas após a retirada das frutas, respectivamente. Esse distúrbio ocorreu com baixa frequiência em pêssegos colhidos mais maduros (estádios III e IV), nunca ultrapassando $5 \%$ das frutas, tanto durante o armazenamento refrigerado (Tabela 3A), quanto após 72 horas a $20 \pm 0,5^{\circ} \mathrm{C}$ (Tabela 3B).

Esses resultados indicam que as frutas da cultivar Chiripá são suscetíveis à ocorrência de lanosidade, que aumenta à medida que se antecipa a colheita e prolonga-se o período de armazenamento.
Comportamento semelhante foi relatado por ROBERTSON et al. (1992), TAYLOR et al. (1994) e MURRAY \& VALENTINI (1998).

Contrariamente à lanosidade, o escurecimento interno de pêssegos da cultivar Chiripá ocorreu com maior incidência em frutas mais maduras (Tabela 4). Entretanto, os valores observados foram relativamente baixos, nunca ultrapassando $10 \%$ das frutas, quando mantidas sob refrigeração (Tabela 4A). Mas quando as frutas foram mantidas a $20 \pm 0,5^{\circ} \mathrm{C}$, durante 72 horas, houve aumento na incidência de escurecimento. A maior incidência foi verificada nos pêssegos colhidos mais maduros (estádio IV), atingindo 100\% das frutas (Tabela 4B).

Pela análise sensorial (Tabela 5), verificou-se que as frutas colhidas nos estádios III e IV apresentaram notas significativamente superiores àquelas dos estádios I e II. Mas, essas frutas colhidas mais maduras têm menor firmeza de polpa e, em consequiência, maior suscetibilidade a danos mecânicos e período de armazenamento e potencial de transporte reduzidos.

\section{CONCLUSÕES}

A colheita dos pêssegos da cultivar Chiripá, em estádios menos avançados de maturação, preserva a firmeza de polpa, mas aumenta a ocorrência de lanosidade e diminui a qualidade sensorial das frutas. Já a colheita tardia melhora a qualidade organoléptica, mas reduz o período de conservação.

Tabela 4 - Ocorrência de escurecimento interno (em percentual de frutas) em pêssegos da cultivar Chiripá, armazenados sob refrigeração durante 42 dias. As avaliações foram realizadas 24 horas (A) e 72 horas (B) após a retirada dos frutos da câmara fria. Pelotas-RS. 1999.

A

\begin{tabular}{cccccc}
\hline \multirow{5}{*}{$\begin{array}{c}\text { Período } \\
\text { (dias) }\end{array}$} & E I & E II & E III & E IV & Média \\
\cline { 2 - 6 } & & & & & \\
\hline & & & & & \\
0 & $0,00^{\mathrm{Aa} *}$ & $0,00^{\mathrm{Ca}}$ & $0,00^{\mathrm{Ea}}$ & $0,00^{\mathrm{Da}}$ & 0,00 \\
7 & $0,00^{\mathrm{Ab}}$ & $0,00^{\mathrm{Cb}}$ & $0,00^{\mathrm{Eb}}$ & $5,32^{\mathrm{Ca}}$ & 1,33 \\
14 & $0,00^{\mathrm{Ab}}$ & $0,00^{\mathrm{Cb}}$ & $0,00^{\mathrm{Eb}}$ & $7,32^{\mathrm{Ba}}$ & 1,83 \\
21 & $0,00^{\mathrm{Ac}}$ & $0,00^{\mathrm{Cc}}$ & $3,96^{\mathrm{Db}}$ & $10,33^{\mathrm{Aa}}$ & 3,57 \\
28 & $0,00^{\mathrm{Ac}}$ & $4,97^{\mathrm{Bb}}$ & $5,32^{\mathrm{Ca}}$ & & 3,43 \\
35 & $0,00^{\mathrm{Ac}}$ & $4,97^{\mathrm{Bb}}$ & $7,98^{\mathrm{Ba}}$ & & 4,31 \\
42 & $0,00^{\mathrm{Ac}}$ & $7,98^{\mathrm{Ab}}$ & $8,98^{\mathrm{Aa}}$ & & 5,65 \\
& & & & & \\
Média & 0,00 & 2,56 & 3,75 & 5,74 & \\
CV $(\%)$ & & & 7,13 & &
\end{tabular}

B

\begin{tabular}{|c|c|c|c|c|c|}
\hline \multirow{2}{*}{$\begin{array}{c}\text { Período } \\
\text { (dias) }\end{array}$} & \multicolumn{5}{|c|}{ Estádios (72 horas) } \\
\hline & E I & E II & E III & E IV & Média \\
\hline 0 & $0,00^{\mathrm{Ca}}$ & $0,00^{\mathrm{Ea}}$ & $0,00^{\mathrm{Fa}}$ & $0,00^{\mathrm{Da}}$ & 0,00 \\
\hline 7 & $0,00^{\mathrm{Cb}}$ & $0,00^{\mathrm{Eb}}$ & $0,00^{\mathrm{Fb}}$ & $7,98^{\mathrm{Ca}}$ & 1,99 \\
\hline 14 & $0,00^{\mathrm{Cc}}$ & $0,00^{\mathrm{Ec}}$ & $2,94^{\mathrm{Eb}}$ & $9,66^{\mathrm{Ba}}$ & 3,15 \\
\hline 21 & $0,00^{\mathrm{Cd}}$ & $1,91^{\mathrm{Dc}}$ & $4,97^{\mathrm{Db}}$ & $100,0^{\mathrm{Aa}}$ & 26,72 \\
\hline 28 & $2,94^{\mathrm{Bc}}$ & $4,97^{\mathrm{Cb}}$ & $9,98^{\mathrm{Ca}}$ & & 5,96 \\
\hline 35 & $5,00^{\mathrm{Ac}}$ & $6,98^{\mathrm{Bb}}$ & $11,98^{\mathrm{Ba}}$ & & 7,98 \\
\hline 42 & $4,97^{\mathrm{Ac}}$ & $9,98^{\mathrm{Ab}}$ & $16,99^{\mathrm{Aa}}$ & & 10,65 \\
\hline Média & 1,84 & 3,40 & 6,69 & 29,41 & \\
\hline $\mathrm{CV}(\%)$ & & & 6,22 & & \\
\hline
\end{tabular}

* Médias não seguidas por mesma letra, maiúscula na coluna e minúscula na linha, dentro de cada avaliação diferem entre si pelo teste de Duncan, em nível de $5 \%$ de probabilidade de erro. 
Tabela 5 - Nota da análise sensorial (escala de 0-10) em pêssegos da cultivar Chiripá, armazenados sob refrigeração durante 42 dias. As avaliações foram realizadas 24 horas (A) e 72 horas (B) após a retirada dos frutos da câmara fria. Pelotas-RS. 1999.

A

\begin{tabular}{|c|c|c|c|c|c|}
\hline \multirow{2}{*}{$\begin{array}{c}\text { Período } \\
\text { (dias) }\end{array}$} & \multicolumn{5}{|c|}{ Estádios (24 horas) } \\
\hline & E I & E II & E III & E IV & Média \\
\hline 0 & $2,00^{\mathrm{Abd} *}$ & $4,00^{\mathrm{Ac}}$ & $7,00^{\mathrm{Ab}}$ & $9,00^{\mathrm{Aa}}$ & 5,50 \\
\hline 7 & $1,00^{\mathrm{Bd}}$ & $4,00^{\mathrm{Ac}}$ & $7,00^{\mathrm{Ab}}$ & $9,00^{\mathrm{Aa}}$ & 5,25 \\
\hline 14 & $2,00^{\mathrm{ABd}}$ & $5,00^{\mathrm{Ac}}$ & $6,00^{\mathrm{ABb}}$ & $8,00^{\mathrm{Aa}}$ & 5,25 \\
\hline 21 & $3,00^{\mathrm{Ac}}$ & $4,00^{\mathrm{Ab}}$ & $5,00^{\mathrm{Ba}}$ & $1,00^{\mathrm{Bd}}$ & 3,25 \\
\hline 28 & $2,00^{\mathrm{ABc}}$ & $4,00^{\mathrm{Ab}}$ & $5,00^{\mathrm{Ba}}$ & & 3,66 \\
\hline 35 & $2,00^{\mathrm{ABc}}$ & $4,00^{\mathrm{Ab}}$ & $5,00^{\mathrm{Ba}}$ & & 3,66 \\
\hline 42 & $2,00^{\mathrm{ABc}}$ & $4,00^{\mathrm{Ab}}$ & $5,00^{\mathrm{Ba}}$ & & 3,66 \\
\hline Média & 2,00 & 4,14 & 5,71 & 6,75 & \\
\hline $\mathrm{CV}(\%)$ & & & 14,68 & & \\
\hline
\end{tabular}

B

\begin{tabular}{lccccc}
\hline & \multicolumn{5}{c}{ Estádios (72 horas) } \\
(dias) & E I & E II & E III & E IV & Média \\
\cline { 2 - 6 } & & & & & \\
\hline & & & & & \\
0 & $2,00^{\mathrm{Cd}}$ & $7,00^{\mathrm{Ac}}$ & $9,00^{\mathrm{Ab}}$ & $10,00^{\mathrm{Aa}}$ & 7,00 \\
7 & $2,00^{\mathrm{Cd}}$ & $6,00^{\mathrm{Bc}}$ & $7,00^{\mathrm{Bb}}$ & $8,00^{\mathrm{Ba}}$ & 5,75 \\
14 & $3,00^{\mathrm{Bc}}$ & $6,00^{\mathrm{Ba}}$ & $5,00^{\mathrm{Cb}}$ & $5,00^{\mathrm{Cb}}$ & 4,75 \\
21 & $4,00^{\mathrm{Ab}}$ & $5,00^{\mathrm{Ca}}$ & $4,00^{\mathrm{Db}}$ & $1,00^{\mathrm{Dc}}$ & 3,50 \\
28 & $2,00^{\mathrm{Cc}}$ & $3,00^{\mathrm{Db}}$ & $4,00^{\mathrm{Da}}$ & & 3,00 \\
35 & $1,00^{\mathrm{Dc}}$ & $2,00^{\mathrm{Eb}}$ & $3,00^{\mathrm{Ea}}$ & & 2,00 \\
42 & $1,00^{\mathrm{Dc}}$ & $2,00^{\mathrm{Eb}}$ & $3,00^{\mathrm{Ea}}$ & & \\
& & & & & \\
Média & 2,14 & 4,43 & 5,00 & 6,00 & \\
CV (\%) & & \multicolumn{5}{c}{12,43} \\
\end{tabular}

* Médias não seguidas por mesma letra, maiúscula na coluna e minúscula na linha, dentro de cada avaliação diferem entre si pelo teste de Duncan, em nível de $5 \%$ de probabilidade de erro.

Quando os pêssegos são destinados ao armazenamento refrigerado, recomenda-se a colheita no estádio II de maturação (coloração de fundo verde-esbranquiçada, 60 a $70 \mathrm{~N}$ de FP, 12,5 a $13,5^{\circ} \mathrm{Brix}$ e acidez de 8 a $10 \mathrm{cmol} . \ell^{-1}$ ), com um período seguro de estocagem de 21 dias. Quando a comercialização dos pêssegos estiver programada para períodos de até sete dias, podem-se colhê-los no estádio III (coloração de fundo verde-esbranquiçada transparente, 45 a $60 \mathrm{~N}$ de FP, 13,5 a $14,0{ }^{\circ}$ Brix e acidez de 6 a $8 \mathrm{cmol}$. $\left.\ell^{-1}\right)$. Não se recomenda a colheita de pêssegos Chiripá no estádio I (coloração de fundo verdeopaca, 70 a $80 \mathrm{~N}$ de FP, 12,0 a $12,5^{\circ}$ Brix e acidez de 10 a $12 \mathrm{cmol} . \ell^{-1}$ ) devido, sobretudo, à baixa qualidade sensorial.

Os pêssegos da cultivar Chiripá são mais suscetíveis à ocorrência de lanosidade do que de escurecimento interno.

\section{AGRADECIMENTOS}

À FAPERGS pelo auxílio financeiro, ao CNPq e à CAPES pela concessão de bolsas de estudo.

\section{REFERÊNCIAS BIBLIOGRÁFICAS}

BEN-ARIE R., SONEGO, L. Pectolytic enzyme activity involved in wolly breakdown of stored peaches. Phytochemistry, Oxford, v.19, p.2553-2555, 1980.
GOTTINARI, R., ROMBALDI, C.V., ARAÚJO, P.J. Frigoconservação de pêssegos da cultivar BR1. Revista Brasileira de Agrociência, Pelotas, v.4, n.1, p.47-54, 1998.

LUCHSINGER, L. E., WALSH, C.S., SMITH, M. Chilling injury of peach fruits during storage. Horticulturae Science, Wellesbourne, v.25, n.5, p.31-36, 1996.

LURIE, S. Controlled atmosphere storage to decrease physiological disorders in nectarines. Journal of Food Science and Technology, Mysore, n.27, p.507-514, 1992.

LURIE, S. Modified atmosphere storage of peaches and nectarines to reduce storage disorders. Journal of Food Quality, Oxford, v.16, p.56-65, 1993.

MANESS, N.O., CHRIZ, D., HEDGE, S., et al. Cell wall changes in ripening peach fruit from cultivar differing in softening rate. Acta Horticulturae, Wageningen, n.343, p.200-203, 1993.

MEDEIROS. C.A.B., RASEIRA, M.C.B. A cultura do pessegueiro. Brasilia : EMBRAPA-SPI; Pelotas : EMBRAPACPACT, 1998. 251p.

MEREDITH, I.I., ROBERTSON, A.J., HORVAT, R. Changes in physical and chemical parameteres associated with quality and postharvest ripening of harvested peaches. Journal of Agricultural and Food Chemistry, Washington, n.37, p.1210-1214, 1989.

MITCHELL, F.G., CRISOSTO, C.H. The use cooling and cold storage to stabilize and preserve fresch stone fruits. In: VENBRELl, M., AUDERGON, J.M. Post-harvest quality and derived products in stone-fruits. Leida: IRTA, 1995. p.125-137. 
MURRAY, R., VALENTINI, G. Storage and quality of peach fruit harvest at different stages of maturity. Acta Horticulturae, Wageningen, v.2, n.465, p.455-463, 1998.

PRATELlA, G.C., BIONDI, G., BASSI, R. Indici di maturazione per la raccolta: valutazione objetiva per il miglioramento qualitativo delle pesche. Rivista di Frutticoltura, Bologna, n.12, p.75-80, 1988

PRESSEY, R., AVANTS, J.K. Difference in polygalacturonase composition of clingstone and freestone peaches. Journal of Food Science, Chicago, v.43, p.1415-1417, 1978.

ROBERTSON, J.A., MEREDITH, F.I., FORBUS, W.R.J., et al. Relatioship of quality characteristics of peaches to maturity. Journal of Food Science, Chicago, v.57, n.6, p.1401-1404, 1992.

SALVADOR, M.E., LIZANA, L.A., LUCSINGER, L.E., $\boldsymbol{e}$ t al Loclity effect on some fruit quality parameters in peaches and nectarines. Acta Horti Culturae, Wageningen, v.2, n.465, p.447-451, 1998
SONEGO, L., BEM-ARIE, R., RAYNAL, J., et al. Biochemical and physical evaluation of textural characteristics of nectarines exhibiting wolly breakdown. Postharvest Biology and Technology, Amsterdam, v.54, p.58-62, 1994.

SOUTY, M., AUDERGON, J.M., CHAMBROY, Y. Les critères de qualité. L'arboriculture frutière, Paris-France, n.430, p.18-24, 1990.

TAYLOR, M.A., RABE, E., GOOD, M.C., et al. Effect of storage regimes on pectolytic enzymes, pectic substances, internal conductivity and gel breakdown in col storage songold plums. Journal of Horti Cultural Science, Ashford, v.69, p.527-534, 1994.

TONUTTI, P., BONGHI, C., VIDRICH, R., et al. Molecular and biochemical effects of anoxia, hypoxia and $\mathrm{CO}_{2}$-enriched atmosphere on Springcrest peaches. Acta Horti Culturae, Wageningen, v.2, n.465. p.439-446, 1998.

Ciência Rural, v. 31, n. 1, 2001. 